\title{
Dopaminergic drugs and the risk of hip or femur fracture: a population-based case-control study
}

\author{
M. E. L. Arbouw - K. L. L. Movig • T. P. van Staa • \\ A. C. G. Egberts • P. C. Souverein - F. de Vries
}

Received: 28 April 2010 /Accepted: 30 August 2010 /Published online: 22 October 2010

(C) The Author(s) 2010. This article is published with open access at Springerlink.com

\begin{abstract}
Summary The effect of dopaminergic medication on the risk of hip/femur fractures is not clear. Our results showed a nearly twofold increased risk of hip/femur fractures in current dopaminergic drug users. Concomitant use of antidepressants further increased this risk. Fracture risk assessment may be warranted in elderly users of dopaminergic drugs.

Introduction Dopaminergic drugs, often used in the treatment of Parkinson's disease, have several pharmacological effects that may increase or decrease the risk of falling and fractures. Thus, the effect of dopaminergic medication on the risk of hip/femur fractures is not clear. The objective of the study was to examine the effect of dopaminergic medication and concomitant use of psychotropics on the risk of hip/femur fractures taking into account the timing of dopaminergic drug use.
\end{abstract}

\footnotetext{
M. E. L. Arbouw · T. P. van Staa - A. C. G. Egberts •

P. C. Souverein $\cdot$ F. de Vries $(\square)$

Department of Pharmacoepidemiology and Pharmacotherapy, Utrecht Institute for Pharmaceutical Sciences, Faculty of Science, Universiteit Utrecht,

P.O. Box 80082, 3508 TB Utrecht, The Netherlands

e-mail: f.devries@uu.nl
}

M. E. L. Arbouw • A. C. G. Egberts

Department of Clinical Pharmacy, University Medical Center

Utrecht,

Utrecht, The Netherlands

M. E. L. Arbouw $\cdot$ K. L. L. Movig

Department of Clinical Pharmacy, Medisch Spectrum Twente,

Enschede, The Netherlands

T. P. van Staa $\cdot$ F. de Vries

MRC Epidemiology Resource Centre, University of

Southampton, Southampton General Hospital,

Southampton, UK
Methods A population-based case-control study in the PHARMO database was conducted for the period 1991 to 2002. Cases were patients aged 18 years and older with a first hip or femur fracture and matched to four control patients by year of birth, sex and geographical region.

Results The study population included 6,763 cases and 26,341 controls. Current use of dopaminergic drugs (130 days before the index date) was associated with an increased risk of hip/femur fractures compared to never use $\left(\mathrm{OR}_{\text {adj }} 1.76,95 \% \mathrm{CI}=1.39-2.22\right)$, but this excess risk rapidly dropped to baseline levels when treatment had been discontinued $>1$ year ago. Concomitant use of antidepressants among current dopaminergic drug users further increased the risk of hip/femur fractures $\left(\mathrm{OR}_{\text {adj }} 3.51,95 \%\right.$ $\mathrm{CI}=2.10-5.87$ ) while there was no additional risk with concomitant use of other psychotropics.

Conclusions Although the observed association between dopaminergic drugs and fracture risk may not be entirely causal, due to absence of information on the (severity of the) underlying disease, fracture risk assessment may be warranted in elderly users of dopaminergic drugs.

Keywords Dopaminergic drugs $\cdot$ Femur fractures $\cdot$ Hip fractures · Parkinson's disease
Abbreviations
CI Confidence interval
OR Odds ratios
PD Parkinson's disease

\section{Introduction}

Dopaminergic drugs are commonly used in the treatment of Parkinson's disease (PD), a neurodegenerative movement 
disorder characterised by tremor, rigidity, akinesia and postural instability [1]. PD has a prevalence of approximately $0.5 \%$ to $1 \%$ among persons 65 to 69 years of age, rising to $1-3 \%$ among persons 80 years of age and older [2].

Several studies have shown increased non-spine fracture incidence rates in PD [3-6]. The main risk factors are falls [7], due to the underlying balance disorder, and lower bone mineral density (BMD) $[5,6]$, which may be caused by immobilisation [8], inadequate vitamin D intake [9], insufficient sun exposure [10] and a lower body mass index (BMI) [11]. Falls are the most common primary reason for emergency hospital admission in patients with PD [12].

The effect of dopaminergic drugs on fracture risk is relatively unexplored. Dopaminergic drugs can be divided into the dopamine precursor, levodopa, and the directacting dopamine agonists. Side effects associated with dopaminergic drug use include orthostatic hypotension [13], sudden onset of sleep [14], daytime sleepiness [15] and dizziness, all of which may increase the risk of falls and subsequent fractures. In addition, levodopa use can induce hyperhomocysteinemia, which has been suggested as a mechanistic risk factor for fractures [16]. In contrast, several factors related to dopaminergic drug use may reduce fracture risk. Treatment of PD with dopaminergic drugs may improve the locomotor function and thus prevent falls. Furthermore, although speculative, dopaminergic drugs may decrease fracture risk by suppressing prolactin levels, thereby improving secretion of gonadal steroids and thus increasing BMD [17, 18].

In a Danish epidemiological study, higher doses of levodopa have been associated with an increased risk of hip fractures [17]. This finding was explained by better mobilisation of patients in the absence of completely normalised movement patterns, leading to an increased risk of falls and fractures. It remains unclear what the influence is of continuous duration of use or discontinuation of dopaminergic drugs on the risk of hip fractures.

A substantial number of patients with PD suffer from depression (20-40\%) [19] and concomitantly use antidepressants (23\%) [20]. Both have been previously identified as independent risk factors for hip fractures [21-23]. The effect of concomitant use of dopaminergic drugs and antidepressants on the risk of hip fractures is unclear. Also, antipsychotics are used frequently in patients with PD (7year probability of use 35\%) [24]. Its use has been associated with a higher risk of hip/femur fractures [25, 26], but the effect of concomitant use of dopaminergic drugs and antipsychotics has not been studied.

The aim of this study was to examine the association between use of dopaminergic drugs and the risk of hip/ femur fractures and particularly the timing of dopaminergic drug use and excess fracture risk. Furthermore, the effect of concomitant use of psychotropic and dopaminergic drugs on the risk of hip/femur fractures was evaluated.

\section{Methods}

Study design

We conducted a case-control study within the Dutch PHARMO Record Linkage System (RLS) [Institute for Drug Outcome Research, www.pharmo.nl]. The database includes the demographic details and complete medication histories for about one million community-dwelling residents in the Netherlands representing some $7 \%$ of the general population. Almost every individual in the Netherlands is registered with a single community pharmacy, independent of prescriber and irrespective of their health insurance or socioeconomic status.

In the organisation of pharmaceutical care, Dutch community pharmacies play a central role. These pharmacies are typically 3-4 times larger than their counterparts in other Western European countries or North America, having 8,000-14,000 patients per pharmacy. Pharmacy networks in PHARMO typically comprise a sample of pharmacies in different geographic regions, with careful geographical selection of urban and rural community pharmacies. The provision of pharmaceutical services from Dutch pharmacies is population-based. Specific populations (e.g. the very poor, the unemployed) are therefore not excluded from pharmaceutical services. This is an important issue with respect to external validity to populations outside the PHARMO database. Validation studies on PHARMO RLS have confirmed a high level of data completeness and validity with regards to fractures [27, 28].

\section{Study population}

Data were collected for the period 1 January 1991 to 31 December 2002. Cases were patients aged 18 years and older with a record for a first fracture of the hip or femur during the study period. The index date was the date of hospital admission. Each case was matched to up to four control patients by year of birth, sex and geographical region. Each control was assigned the same index date as the corresponding case.

\section{Exposure assessment}

Exposure to dopaminergic drugs was determined by reviewing dispensing information prior to the index date: (a) dopamine agonists: bromocriptine, lisuride, pergolide, ropinirole, pramipexole, cabergoline and apomorphine (excluding the sublingual administration form) and (b) 
levodopa-containing drugs. The indications these drugs were prescribed for were not recorded in the PHARMO database.

For each dispensing of a dopaminergic drug, the written dosage instruction was used to estimate its exposure episode. If a written dosage instruction was missing, the median value of all dispensings was used. 'Current' users were patients who were exposed to dopaminergic drugs within the 30-day period before the index date. 'Recent' users had discontinued dopaminergic drugs between 31 and 182 days before the index date. 'Past' users had stopped taking dopaminergic drugs $>182$ days before the index date.

Concomitant exposure to psychotropics [anticholinergics (biperiden, dexetimide, orphenadrine, procyclidine, trihexyphenidyl), antidepressants, antipsychotics and benzodiazepines] was measured within the current dopaminergic drug users. For each current dopaminergic drug user, the continuous duration of use was determined by adding up all dopaminergic exposure episodes before the index date. If the period between two exposure episodes exceeded 3 months, this was considered a treatment gap. Exposure episodes before a treatment gap were not added to the total period of continuous duration of use.

\section{Potential confounders}

The records of cases and controls were reviewed for evidence of potential confounders that have previously been associated with fracture risk [29, 30]. These include the following 30 variables: a recent history of hospitalisation (in the previous year) for: mental disorders, and skin/subcutaneous diseases; a history of hospitalisation at any time for: impaired renal function, malignant neoplasm, endocrine disorder, cardiovascular disease, cerebrovascular disease, obstructive airway disease, inflammatory bowel disease, musculoskeletal or connective tissue disease, rheumatoid arthritis and PD; dispensing of a benzodiazepine within 3 months before the index date; dispensing within the previous 6 months of any of the following: antipsychotics, bronchodilators, inhaled or oral corticosteroids, hormone replacement therapy, antidepressants, antiarrhythmics, antiepileptics, thiazide diuretics, thyroid hormones, antithyroid hormones, drugs for treatment of diabetes, disease-modifying anti-rheumatic drugs, two or more dispensings of a non-steroidal anti-inflammatory drug; and current use of the following antiparkinsonian drugs: amantadine, selegeline, tolcapone and entacapone.

\section{Data analysis}

Conditional logistic regression analysis was used to estimate the risk of hip/femur fracture associated with the use of dopaminergic drugs and were expressed as odds ratios (OR) with corresponding 95\% confidence intervals (CI). Adjusted odds ratios $\left(\mathrm{OR}_{\mathrm{adj}}\right)$ for hip/femur fracture were estimated after adjustment for the various confounding variables. Final regression models included all potential confounding factors that changed the natural logarithm of the risk estimate with more than $5 \%$.

Stratified analyses within current dopaminergic drug users were performed regarding gender, age category, type of current dopaminergic drug (dopamine agonist, levodopa-containing drug, or combined use) and concomitant use of anticholinergics, antidepressants, antipsychotics or benzodiazepines.

In order to differentiate between onset and offset of the effect of dopaminergic drugs on hip/femur fractures, two separate analyses were performed: (1) the onset was investigated by calculating the risk of hip/femur fractures in relation to continuous duration of dopaminergic drug use within current users; (2) the offset was investigated by calculating the risk of hip/femur fractures in relation to the recency of use of dopaminergic drug treatment within ever users. In both analyses, the dopaminergic drug users were subdivided into 10 subgroups based on deciles of the continuous duration of use (or recency of use). An OR was calculated for each of the subgroups. Spline regression was then used to smooth these estimates and to visualise any trends. This method has been advocated as an alternative to categorical analysis [31]. Analyses were performed with SPSS 16.0. Spline regression was performed with SAS 9.1.3.

\section{Results}

We identified 6,763 cases with a fracture of the hip or femur and 26,341 matched controls (Table 1). Almost three-quarters $(73 \%)$ of the study population was female. The mean duration of follow-up before the index date was 5.8 years for cases and 5.7 years for controls. The median age was 79 years for cases and controls. More details on this particular dataset have been described elsewhere [26, 32, 33].

As shown in Table 2, the risk of hip/femur fractures was nearly doubled among current users of dopaminergic drugs compared to no use $\left(\mathrm{OR}_{\mathrm{adj}}=1.76,95 \% \mathrm{CI}=1.39-2.22\right)$. The risk associated with current use of dopaminergic drugs was significantly greater compared with past use $(p=0.019)$. Further stratified analyses suggested that the risk of hip/ femur fracture for current users of dopaminergic drugs were not different for men and women. There were no risk differences for individuals aged $\geq 70$ years compared with those younger than 70 years.

Table 3 shows that the risk of hip/femur fractures was comparable among current users of dopamine agonists only, 
Table 1 Characteristics of cases and controls

\begin{tabular}{|c|c|c|c|}
\hline & Cases $(n=6,763), \%$ & Controls $(n=26,341), \%$ & Crude OR $[95 \% \mathrm{CI}]$ \\
\hline \multicolumn{4}{|l|}{ Gender } \\
\hline Male & $1,834(27.1)$ & $7,203(27.3)$ & \\
\hline Female & $4,929(72.9)$ & $19,138(72.7)$ & \\
\hline \multicolumn{4}{|l|}{ Age (years) } \\
\hline $18-49$ & $452(6.7)$ & $1,808(6.9)$ & \\
\hline $50-69$ & $1,061(15.7)$ & $4,239(16.1)$ & \\
\hline$\geq 70$ & $5,250(77.6)$ & $20,294(77.0)$ & \\
\hline \multicolumn{4}{|l|}{ Hospitalisation before the index date } \\
\hline Cardiovascular disease & $359(5.3)$ & $1,289(4.9)$ & $1.10[0.98-1.25]$ \\
\hline Cerebrovascular disease & $296(4.4)$ & $565(2.1)$ & $2.12[1.84-2.45]$ \\
\hline Parkinson's disease & $23(0.3)$ & $41(0.2)$ & $2.24[1.34-3.75]$ \\
\hline Mental disorders & $24(0.4)$ & $36(0.1)$ & $2.54[1.51-4.27]$ \\
\hline \multicolumn{4}{|l|}{ Drug use 6 months before the index date } \\
\hline Benzodiazepines $^{\mathrm{a}}$ & $967(14.3)$ & $2,751(10.4)$ & $1.44[1.33-1.56]$ \\
\hline Antidepressants & $643(9.5)$ & $1,343(5.1)$ & $2.00[1.81-2.21]$ \\
\hline Antipsychotics & $412(6.2)$ & $921(3.5)$ & $1.79[1.58-2.02]$ \\
\hline \multicolumn{4}{|l|}{ Current drug use at index date } \\
\hline Amantadine & $30(0.4)$ & $42(0.2)$ & $2.78[1.74-4.44]$ \\
\hline Selegeline & $56(0.8)$ & $51(0.2)$ & $4.37[2.98-6.41]$ \\
\hline Anticholinergics & $43(0.6)$ & $67(0.3)$ & $2.52[1.72-3.70]$ \\
\hline Cathechol- $O$-methyltransferase inhibitors & $1(0.0)$ & $5(0.0)$ & $0.80[0.09-6.85]$ \\
\hline
\end{tabular}

a 3 months before the index date

levodopa only and concomitant users. Furthermore, it shows that concomitant use of antidepressants and dopaminergic drugs further increased the risk of hip/femur fractures $\left(\mathrm{OR}_{\mathrm{adj}}=3.51,95 \% \mathrm{CI}=2.10-5.87\right)$. Concomitant current use of dopaminergic drugs and anticholinergics or antipsychotics or benzodiazepines did not significantly alter the overall risk of hip/femur fractures.

Figure 1 shows that hip/femur fracture risk was increased immediately after initiation of dopaminergic drug therapy and that it remained more than twofold increased

Table 2 Use of dopaminergic drugs and risk of hip/femur fracture

\begin{tabular}{|c|c|c|c|c|}
\hline & Cases $(n=6,763), \%$ & Controls $(n=26,341), \%$ & Crude OR $[95 \% \mathrm{CI}]$ & $\mathrm{OR}_{\mathrm{adj}}^{\mathrm{a}}[95 \% \mathrm{CI}]$ \\
\hline Never use & $6,578(97.3)$ & $25,996(98.7)$ & Reference & Reference \\
\hline Ever use & $185(2.7)$ & $345(1.3)$ & $2.13[1.77-2.56]$ & $1.50[1.22-1.84]$ \\
\hline \multicolumn{5}{|l|}{ Among ever users of a dopaminergic drug } \\
\hline Past use ( $>182$ days before the index date) & $20(0.3)$ & $81(0.3)$ & $0.98[0.59-1.60]$ & $0.91[0.55-1.51]$ \\
\hline Recent use (31-182 days before the index date) & $9(0.1)$ & $27(0.1)$ & $1.28[0.60-2.73]$ & $1.01[0.47-2.20]$ \\
\hline Current use (1-30 days before the index date) & $156(2.3)$ & $237(0.9)$ & $2.62[2.13-3.22]$ & $1.76[1.39-2.22]^{\mathrm{b}}$ \\
\hline \multicolumn{5}{|l|}{ By gender } \\
\hline Male & $45(0.7)$ & $64(0.2)$ & $2.83[1.92-4.17]$ & $1.84[1.21-2.81]$ \\
\hline Female & $111(1.6)$ & $173(0.7)$ & $2.54[1.99-3.24]$ & $1.73[1.32-2.26]$ \\
\hline \multicolumn{5}{|l|}{ By age category (years) } \\
\hline $18-69$ & $13(0.2)$ & $20(0.1)$ & $2.60[1.29-5.23]$ & $1.54[0.73-3.24]$ \\
\hline$\geq 70$ & $143(2.1)$ & $217(0.8)$ & $2.62[2.11-3.25]$ & $1.78[1.39-2.27]$ \\
\hline
\end{tabular}

a Adjusted for: (a) a history in the past year of hospitalisation for Parkinson's disease; (b) use in the past 6 months of antidepressants; and (c) current use of amantadine, selegeline and anticholinergics

${ }^{\mathrm{b}} p=0.019$ for current dopaminergic drug use versus past use 
Table 3 Current use of dopaminergic drugs and risk of hip/femur fracture by substance and concomitant use of anticholinergics, antidepressants, antipsychotics or benzodiazepines

$$
\text { Cases }(n=6,763) \quad \text { Controls }(n=26,341) \quad \text { Crude OR }[95 \% \mathrm{CI}] \quad \mathrm{OR}_{\text {adj }}{ }^{\mathrm{a}}[95 \% \mathrm{CI}]
$$

Among current users of a dopaminergic drug

By substance

Dopamine agonist alone

Combination of dopamine agonist and levodopa

By concomitant use ${ }^{\mathrm{b}}$

Anticholinergics $^{\mathrm{c}}$

Yes

No

Antidepressants

Yes

No

Antipsychotics

Yes

No

Benzodiazepines

Yes

No
$5(0.1)$

$117(1.7)$

$34(0.5)$

$7(0.0)$

$188(0.7)$

$42(0.2)$

$\begin{array}{rr}16(0.2) & 28(0.1) \\ 140(2.1) & 209(0.8) \\ 31(0.5) & 30(0.1) \\ 125(1.8) & 207(0.8) \\ & \\ 17(0.3) & 29(0.1) \\ 139(2.1) & 208(0.8) \\ 23(0.3) & 32(0.1) \\ 133(2.0) & 205(0.8)\end{array}$

$2.86[0.91-9.00]$

$1.86[0.56-6.19]$

$2.46[1.95-3.11]$

$1.71[1.32-2.21]$

$3.28[2.09-5.16]$

$1.98[1.20-3.26]$

${ }^{a}$ Adjusted for the same confounders as under Table 2 ((a) except for anticholinergics, (b) except for antidepressants)

${ }^{\mathrm{b}}$ Concomitant current use (1-30 days before the index date)

${ }^{\mathrm{c}}$ Anticholinergics include biperiden, dexetimide, orphenadrine, procyclidine and trihexyphenidyl

${ }^{\mathrm{d}} p=0.011$ for concomitant versus no concomitant use of antidepressants

during more than 6 years of continuous use. There were no significant differences between current users of a dopaminergic drug with a duration $\leq 1$ year $\left(\mathrm{OR}_{\mathrm{adj}}=1.87,95 \% \mathrm{CI}=\right.$ 1.29-2.73) and current users who had been taking the dopaminergic drug $>1$ year $\left(\mathrm{OR}_{\mathrm{adj}}=1.69,95 \% \mathrm{CI}=1.28\right.$ 2.25). Figure 2 shows that after discontinuation of dopaminergic treatment, the increased risk of hip/femur fractures rapidly decreased and that it was no longer increased after 1 year of discontinuation.

\section{Discussion}

Our results showed a nearly twofold increased risk of hip/ femur fractures in current dopaminergic drug users. Prolonged use did not substantially change this risk. After discontinuation of dopaminergic treatment, the increased risk of hip/femur fractures rapidly decreased and it was no longer increased after 1 year of discontinuation. Patients who used dopaminergic drugs and antidepressants at the same time had a 3.5-fold increased risk of hip/femur fracture.

The findings of this study are to some extent in line with the findings of Vestergaard and coworkers [17]. They reported an association between levodopa use and an increased overall fracture risk and an increased hip fracture risk with high doses of levodopa. In addition, they found an association between dopamine agonists in median dose and an increased hip fracture risk.

In our study, the duration of use in current dopaminergic drug users did not substantially change the risk of hip/ femur fractures. We did notice an increase of the risk estimate directly after initiation of the dopaminergic drug,

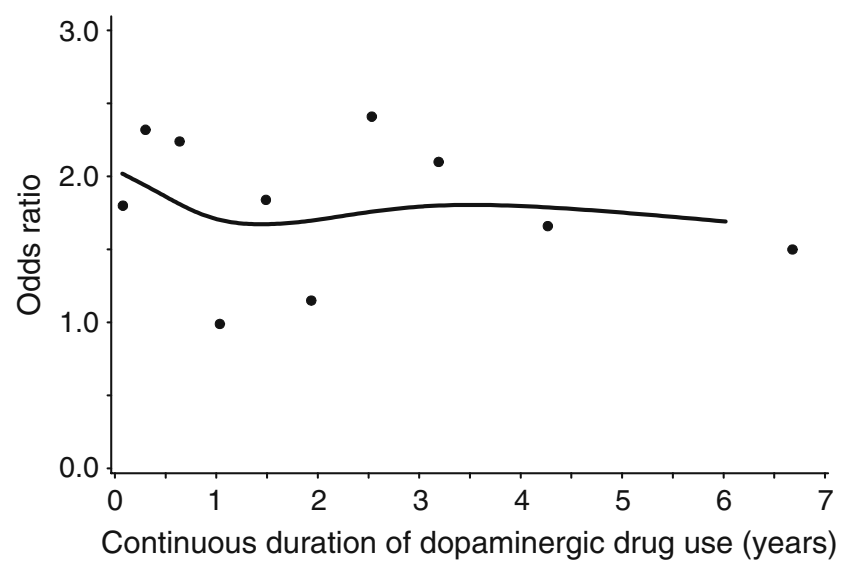

Fig. 1 The risk of hip/femur fracture with continuous duration of dopaminergic drug use among current users. Datapoints and spline regression line represent adjusted OR (adjusted for the same confounders as under Table 2) 


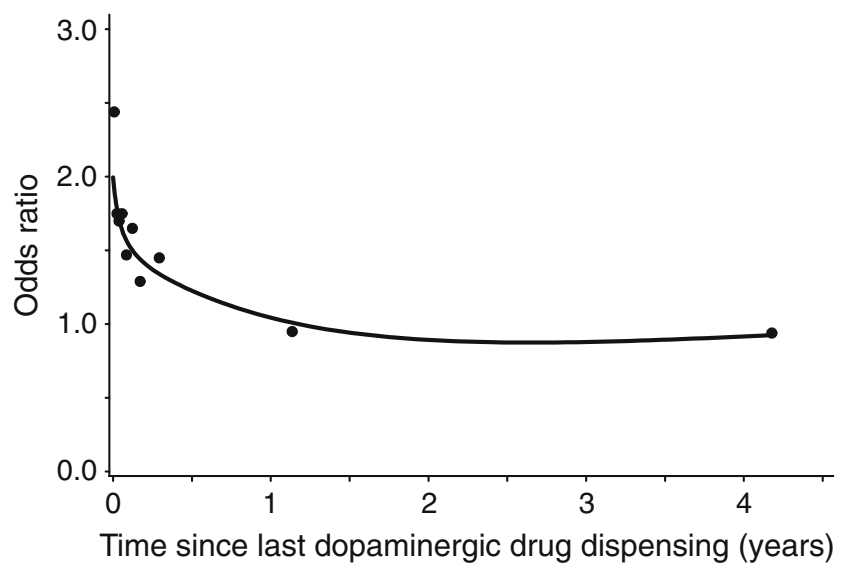

Fig. 2 The risk of hip/femur fracture and time since last dispensing for a dopaminergic drug. Datapoints and spline regression line represent adjusted OR (adjusted for the same confounders as under Table 2)

suggesting that falls are responsible for the increase in fracture risk and not changes in BMD. This may be explained by the fact that dopaminergic drugs could cause postural hypotension, sudden onset of sleep, daytime sleepiness and dizziness, which may lead to an increased risk of falling [34]. One may expect that postural hypotension occurs almost directly after initiation of dopaminergic drug treatment.

The timing of use was found to be important: only current use was associated with a nearly twofold increased risk hip/femur fractures, and the increased risk of hip/femur fractures rapidly decreased after discontinuation. This corroborates the hypothesis that the increased risk is caused by an increased risk of falling rather than an effect on BMD. Unfortunately, we could not formally test this hypothesis due the absence of data on both falls and BMD in our data source.

As a result of potential improvement of BMD due to suppression of prolactin, we hypothesised that dopaminergic drugs could decrease the risk of hip/femur fractures [17, 18]. Even if dopaminergics have a benefit on BMD, it was not sufficient to reduce fracture risk or to balance the increase in fracture risk assumed to be a consequence of an increased falls risk during the first 6-12 months of use. In contrast, it was suggested that levodopa-induced hyperhomocysteinemia could increase the risk of fracture through a direct effect on the bone collagen cross-links [16]. However, in our study, the risk estimate for levodopa users was not different from that of dopamine agonist users alone, or the users of the combination of dopamine agonists and levodopa. Thus, our data do not support this hypothesis. A remark should be made that the group of users of monotherapy dopamine agonists was relatively small.

A substantial number of patients with PD suffer from depression and use antidepressants. Both have been previously identified as independent risk factors for hip fractures [21, 22]. Indeed, patients who used dopaminergic drugs and antidepressants at the same time had the highest risk of hip/femur fracture $\left(\mathrm{OR}_{\mathrm{adj}}=3.51,95 \% \mathrm{CI}=2.10\right.$ 5.87). There are several explanations for this finding. Firstly, the increased risk of fractures may be simply related to a further increased risk of falls [35]. Secondly, it has been suggested that inhibition of the serotonin transporter system by antidepressants have a detrimental effect on bone microarchitecture, leading to a decreased bone strength and a higher probability that a fall will result in a fracture [23]. Furthermore, depression itself has been associated with fractures [22]. Treatment with other psychotropic drugs, such as benzodiazepines, anticholinergics and antipsychotics, is associated with an increased risk of hip/femur fractures, probably caused by an increased risk of falls [25, $26,36]$ and, for antipsychotics, caused by a decreased bone mineralisation leading to weaker bones [37]. However, the risk of hip/femur fracture was not further increased with concomitant use of dopaminergic drugs and these psychotropic drugs.

It is unclear whether the increased risk of hip/femur fractures in users of dopaminergic drugs is related to the pharmacological properties, the underlying disease or the severity of the underlying disease. Van de Vijver et al. have found that the use of antiparkinsonian drugs has a high positive predictive value for $\mathrm{PD}$ in a population aged 55 years and older, especially when levodopa is used [38]. Although we do not have such information for other age categories, we assume that dopaminergic drugs within our cases and controls were mainly used to treat PD, a progressive disease in which postural instability is one of the main symptoms. Several studies have shown increased non-spine fracture incidence rates in PD [3-6]. Parkinsonian patients have been associated with a higher risk of falls [7] and with lower BMD [5, 6, 39]. A limitation is that we had no data on the severity of the underlying disease. However, we did correct for hospitalisation for PD in the adjusted analysis although an inpatient hospitalisation for PD may be a less sensitive measure of PD severity. One may wonder which type of patients discontinued dopaminergic medication because these drugs are the only option for the treatment of motor symptoms in PD. The patients that discontinued dopaminergic drugs more than 1 year ago did not differ from the current users with respect to age. However, we cannot rule out that some discontinuators had a diagnosis different from PD, such as restless legs syndrome, and hence, a lower risk of falls and/or fractures. Further limitations include absence of potentially confounding data on body mass index, smoking status and exercise. Low BMI, low exercise status and smoking are risk factors for fractures [40, 41]. Low BMI and low exercise status also are associated with PD $[8,11]$. By not correcting for 
these potential confounders, we may have overestimated the risk estimate. Smoking is suggested as a protective factor for PD [42]. By not correcting for smoking status, we may have underestimated the risk estimate. The strengths of this study include the following: our population had a substantial sample size and we had routinely collected longitudinal data on drug exposure and hospitalisations. Patients were included irrespective of socioeconomic status: the study was population-based and provided real life data on intake of dopaminergic drugs.

In conclusion, current dopaminergic drug use was associated with a nearly twofold increased risk of hip/ femur fractures. Concomitant use of antidepressants, which is common among patients with PD, further increased the risk of hip/femur fractures. Although the observed association between dopaminergic drugs and fracture risk may not be entirely causal, fracture risk assessment may be warranted in elderly users of dopaminergic drugs.

Conflicts of interest Dr. Van Staa and Dr. de Vries have conducted epidemiological studies for pharmaceutical companies as researchers of the General Practice Research Database Research Division, Medicines and Healthcare Products Regulatory Agency, London, UK. The other authors report no conflicts of interest. The Division of Pharmacoepidemiology \& Pharmacotherapy employing authors Arbouw, van Staa, Egberts, Souverein and de Vries has received unrestricted funding for pharmacoepidemiological research from GlaxoSmithKline, Novo Nordisk, the private-public funded Top Institute Pharma (www.tipharma.nl, includes co-funding from universities, government and industry), the Dutch Medicines Evaluation Board and the Dutch Ministry of Health.

Open Access This article is distributed under the terms of the Creative Commons Attribution Noncommercial License which permits any noncommercial use, distribution, and reproduction in any medium, provided the original author(s) and source are credited.

\section{References}

1. Hoehn MM, Yahr MD (1967) Parkinsonism: onset, progression and mortality. Neurology 17:427-442

2. Tanner CM, Goldman SM (1996) Epidemiology of Parkinson's disease. Neurol Clin 14:317-335

3. Genever RW, Downes TW, Medcalf P (2005) Fracture rates in Parkinson's disease compared with age- and gender-matched controls: a retrospective cohort study. Age Ageing 34:21-24

4. Johnell O, Melton LJ III, Atkinson EJ, O'Fallon WM, Kurland LT (1992) Fracture risk in patients with parkinsonism: a populationbased study in Olmsted County, Minnesota. Age Ageing 21:32-38

5. Fink HA, Kuskowski MA, Taylor BC, Schousboe JT, Orwoll ES, Ensrud KE (2008) Association of Parkinson's disease with accelerated bone loss, fractures and mortality in older men: the Osteoporotic Fractures in Men (MrOS) study. Osteoporos Int 19:1277-1282

6. Schneider JL, Fink HA, Ewing SK, Ensrud KE, Cummings SR (2008) The association of Parkinson's disease with bone mineral density and fracture in older women. Osteoporos Int 19:1093-1097
7. Koller WC, Glatt S, Vetere-Overfield B, Hassanein R (1989) Falls and Parkinson's disease. Clin Neuropharmacol 12:98-105

8. Kamide N, Fukuda M, Miura H (2008) The relationship between bone density and the physical performance of ambulatory patients with Parkinson's disease. J Physiol Anthropol 27:7-10

9. Sato Y, Kaji M, Tsuru T, Oizumi K (2001) Risk factors for hip fracture among elderly patients with Parkinson's disease. J Neurol Sci 182:89-93

10. Bezza A, Ouzzif Z, Naji H, Achemlal L, Mounach A, Nouijai M, Bourazza A, Mossadeq R, El MA (2008) Prevalence and risk factors of osteoporosis in patients with Parkinson's disease. Rheumatol Int 28:1205-1209

11. Bachmann CG, Trenkwalder C (2006) Body weight in patients with Parkinson's disease. Mov Disord 21:1824-1830

12. Woodford H, Walker R (2005) Emergency hospital admissions in idiopathic Parkinson's disease. Mov Disord 20:1104-1108

13. van Dijk JG, Haan J, Zwinderman K, Kremer B, van Hilten BJ, Roos RA (1993) Autonomic nervous system dysfunction in Parkinson's disease: relationships with age, medication, duration, and severity. J Neurol Neurosurg Psychiatry 56:1090-1095

14. Homann CN, Wenzel K, Suppan K, Ivanic G, Kriechbaum N, Crevenna R, Ott E (2002) Sleep attacks in patients taking dopamine agonists: review. BMJ 324:1483-1487

15. Kaynak D, Kiziltan G, Kaynak H, Benbir G, Uysal O (2005) Sleep and sleepiness in patients with Parkinson's disease before and after dopaminergic treatment. Eur J Neurol 12:199-207

16. Sato Y, Iwamoto J, Kanoko T, Satoh K (2005) Homocysteine as a predictive factor for hip fracture in elderly women with Parkinson's disease. Am J Med 118:1250-1255

17. Vestergaard P, Rejnmark L, Mosekilde L (2007) Fracture risk associated with parkinsonism and anti-Parkinson drugs. Calcif Tissue Int 81:153-161

18. Naliato EC, Violante AH, Caldas D, Farias ML, Bussade I, Lamounier FA, Loureiro CR, Fontes R, Schrank Y, Loures T, Colao A (2008) Bone density in women with prolactinoma treated with dopamine agonists. Pituitary 11:21-28

19. Lieberman A (2006) Depression in Parkinson's disease - a review. Acta Neurol Scand 113:1-8

20. Brandt-Christensen M, Garcia LA, Morkeberg NF, Kragh AP, Vedel KL (2007) Parkinson's disease and antidepressant drug treatment: a case-register study. Parkinsonism Relat Disord $13: 406-410$

21. Vestergaard P, Rejnmark L, Mosekilde L (2008) Selective serotonin reuptake inhibitors and other antidepressants and risk of fracture. Calcif Tissue Int 82:92-101

22. Whooley MA, Kip KE, Cauley JA, Ensrud KE, Nevitt MC, Browner WS (1999) Depression, falls, and risk of fracture in older women. Study of Osteoporotic Fractures Research Group. Arch Intern Med 159:484-490

23. van den Brand MW, Samson MM, Pouwels S, van Staa TP, Thio B, Cooper C, Leufkens HG, Egberts AC, Verhaar HJ, De Vries F (2009) Use of anti-depressants and the risk of fracture of the hip or femur. Osteoporos Int 20:1705-1713

24. Marras C, Kopp A, Qiu F, Lang AE, Sykora K, Shulman KI, Rochon PA (2007) Antipsychotic use in older adults with Parkinson's disease. Mov Disord 22:319-323

25. Hugenholtz GW, Heerdink ER, van Staa TP, Nolen WA, Egberts AC (2005) Risk of hip/femur fractures in patients using antipsychotics. Bone 37:864-870

26. Pouwels S, van Staa TP, Egberts AC, Leufkens HG, Cooper C, De Vries F (2009) Antipsychotic use and the risk of hip/femur fracture: a population-based case-control study. Osteoporos Int 20:1499-1506

27. Herings RM, Stricker BH, de Boer A, Bakker A, Sturmans F, Stergachis A (1996) Current use of thiazide diuretics and prevention of femur fractures. J Clin Epidemiol 49:115-119 
28. Herings RM, Stricker BH, de Boer A, Bakker A, Sturmans F (1995) Benzodiazepines and the risk of falling leading to femur fractures. Dosage more important than elimination half-life. Arch Intern Med 155:1801-1807

29. Cummings SR, Nevitt MC, Browner WS, Stone K, Fox KM, Ensrud KE, Cauley J, Black D, Vogt TM (1995) Risk factors for hip fracture in white women. Study of Osteoporotic Fractures Research Group. N Engl J Med 332:767-773

30. van Staa TP, Geusens P, Kanis JA, Leufkens HG, Gehlbach S, Cooper C (2006) A simple clinical score for estimating the longterm risk of fracture in post-menopausal women. QJM 99:673-682

31. Greenland S (1995) Dose-response and trend analysis in epidemiology: alternatives to categorical analysis. Epidemiology 6:356-365

32. De Vries F, Souverein PC, Cooper C, Leufkens HG, van Staa TP (2007) Use of beta-blockers and the risk of hip/femur fracture in the United Kingdom and The Netherlands. Calcif Tissue Int 80:69-75

33. De Vries F, Pouwels S, Lammers JW, Leufkens HG, Bracke M, Cooper C, van Staa TP (2007) Use of inhaled and oral glucocorticoids, severity of inflammatory disease and risk of hip/ femur fracture: a population-based case-control study. J Intern Med 261:170-177

34. Vaserman N (2005) Parkinson's disease and osteoporosis. Joint Bone Spine 72:484-488

35. Thapa PB, Gideon P, Cost TW, Milam AB, Ray WA (1998) Antidepressants and the risk of falls among nursing home residents. N Engl J Med 339:875-882
36. Vestergaard P, Rejnmark L, Mosekilde L (2006) Anxiolytics, sedatives, antidepressants, neuroleptics and the risk of fracture. Osteoporos Int 17:807-816

37. Meaney AM, Smith S, Howes OD, O'Brien M, Murray RM, O'Keane V (2004) Effects of long-term prolactin-raising antipsychotic medication on bone mineral density in patients with schizophrenia. Br J Psychiatry 184:503-508

38. Van de Vijver DA, Stricker BH, Breteler MM, Roos RA, Porsius AJ, de Boer A (2001) Evaluation of antiparkinsonian drugs in pharmacy records as a marker for Parkinson's disease. Pharm World Sci 23:148-152

39. Lorefalt B, Toss G, Granerus AK (2007) Bone mass in elderly patients with Parkinson's disease. Acta Neurol Scand 116:248254

40. Cauley JA, Fullman RL, Stone KL, Zmuda JM, Bauer DC, Barrett-Connor E, Ensrud K, Lau EM, Orwoll ES (2005) Factors associated with the lumbar spine and proximal femur bone mineral density in older men. Osteoporos Int 16:1525-1537

41. Kanis JA, Johnell O, Oden A, Johansson H, De Laet C, Eisman JA, Fujiwara S, Kroger H, McCloskey EV, Mellstrom D, Melton LJ, Pols H, Reeve J, Silman A, Tenenhouse A (2005) Smoking and fracture risk: a meta-analysis. Osteoporos Int 16:155-162

42. Powers KM, Kay DM, Factor SA, Zabetian CP, Higgins DS, Samii A, Nutt JG, Griffith A, Leis B, Roberts JW, Martinez ED, Montimurro JS, Checkoway H, Payami H (2008) Combined effects of smoking, coffee, and NSAIDs on Parkinson's disease risk. Mov Disord 23:88-95 